\title{
Integrated assessment of flood protection measures in the context of climate change: hydraulic modelling and economic approach
}

\author{
B. J. Dewals ${ }^{1,2}$, E. Giron ${ }^{3}$, J. Ernst ${ }^{1}$, W. Hecq ${ }^{3}$ \& M. Pirotton ${ }^{1}$ \\ ${ }^{1}$ Department ArGEnCo, University of Liege, Belgium \\ ${ }^{2}$ Fund for Scientific Research F.R.S.-FNRS, Belgium \\ ${ }^{3}$ Centre for Economic and Social Studies on the Environment, \\ Université Libre de Bruxelles, Belgium
}

\begin{abstract}
In order to protect our societies from damaging impacts of climate change (floods, heat waves, droughts etc), the most cost-effective adaptation measures must be selected among a wide range of options (including structural and nonstructural protection measures). The Belgian national project "ADAPT" aims to provide guidance for this choice by developing a decision-support tool for the selection of protection measures against increased risk resulting from climate change, and more specifically from floods. This tool is based on a combination of cost-benefit analysis (CBA) and multicriteria analysis (MA), taking into consideration hydraulic, economic, social and ecological indicators. In order to demonstrate its efficiency, the method is applied in the two main Belgian river basins (Meuse and Scheldt).

Within this global framework, the present paper covers the description of the hydraulic modelling component and the economic approach, focusing on their interactions, for the case of the Meuse Basin (river Ourthe). The hydraulic simulations are performed with the two-dimensional numerical model WOLF 2D, which is developed at the University of Liege. High resolution Digital Elevation Models are exploited, enabling the representation of streets, buildings and parcels individually. In parallel, for past flood events, a relationship is established between simulated local water depths and actual damage costs, enabling the development and validation of suitable damage functions.

Keywords: climate change, hydrodynamic modelling, damage function, finite volume, digital elevation model, decision support.
\end{abstract}




\section{Introduction}

Climate change is currently regarded as one of the most important threats to the environment and human well-being. This was confirmed recently by the release of the IPCC Working Group II Report on 'impacts, adaptation and vulnerability' (IPCC, April 2007) [12]. It is very likely that our societies will be confronted with increases in temperature, heat waves, heavy precipitation events, incidences of drought and rising sea level. If nothing is done to limit these threats, the phenomena will generate multiple damages that will put an increasing burden on our societies, as is demonstrated by the Stern Review (2006).

Policymakers can respond to these threats in two ways. First, by the development of mitigation measures, with the purpose of reducing GHG emissions, and secondly by the development of adaptation measures that aim to limit the impacts of climate change phenomena on populations and ecosystems.

The Belgian national research project "ADAPT - Towards an integrated decision tool for adaptation measures" focuses on inundation and on the development of corresponding adaptation measures. The project aims to meet the needs to support decision-making on adaptation policy by the development of an integrated decision-support tool for selecting adaptation measures. However, this development of adaptation policies is far from straightforward because of the uncertainties on the extent and the location of climate change impacts.

To develop the tool, the project focuses on the case study of flooding in Belgium. The development of the tool is based on an in-depth study of two case study areas that are located in the two main Belgian river basins (the Scheldt and the Meuse). Those study areas have been selected on the basis of their flood history, as well as their hydraulic, economic, social and ecological features.

By combining inundation maps and land use data, the developed methodology evaluates which elements or assets are affected by a given flooding scenario and how much they are affected in terms of inundation depth or other flooding characteristics [12]. The present paper provides first an overview of this procedure developed to combine hydrodynamic modelling results with the economic analysis of the impacts of flooding (section 2). Second, the hydrodynamic modelling (section 3 ) and the economic damage evaluation (section 0 ) are subsequently described in detail.

\section{Overview of the integration between flood modelling and evaluation of economic damage}

As shown in Figure 1, the evaluation of the risk associated to floods relies basically on two main parameters: the probability of occurrence of a flood, which can be related to the statistically calculated return period of the corresponding discharge, and its consequences. Consequently, the risk can be evaluated mathematically by the product of the probability times the consequences, summed over each individual event.

The probability of occurrence of a flood event is ascertained by statistical hydrological methods that assigns a return period (in years) to a given discharge. 
FLOOD RISK $=$ sum ( probability $*$ consequences $)$

\begin{tabular}{|c|c|c|c|}
\hline Probability & \multicolumn{3}{|c|}{ Consequences (actual predicted damage) } \\
\hline Probability & Exposure & Elements-at-risk & Vulnerability \\
& (extent, depth, & $\begin{array}{c}\text { (people, buildings, } \\
\text { roads, networks, } \\
\text { eco-systems ...) }\end{array}$ & $\begin{array}{c}\text { (susceptibility, } \\
\text { adaptative capacity, } \\
\text { resilience, ...) }\end{array}$ \\
\hline
\end{tabular}

Figure 1: Main components of flood risk evaluation.

The major components to be considered for quantifying the consequences are the exposure, the elements-at-risk and their vulnerability.

The exposure characterizes the inundation by means of the three following features: inundation extent, water depth and flow velocity. This information is directly provided for instance by a 2D hydrodynamic modelling of the flood. Additional information may also be relevant, such as flood duration or water quality indicators.

Second, the elements-at-risk must be clearly identified. Indeed, flood damages would obviously remain extremely low if the inundated area, whatever its extent, contains no element of socio-economic (or ecologic) importance. For instance, for given flow conditions, the "flood risk" would vary significantly depending on whether the inundation takes place in a densely populated area or in a rural one...

For large scale studies (e.g. regional or national), the elements-at-risk may be estimated by a percentage of the total studied area [17], while for more detailed analysis, they are identified individually by means of land use database.

Finally, the vulnerability of the elements-at-risk (depending on their susceptibility, adaptative capacity and resilience) is introduced in the risk analysis by means, for instance, of damage functions (section 0 ).

In the present study, the consequences are preliminarily restricted to the economic damage, in such a way that the flood risk can be quantified by a monetary value (€/year). Therefore, economic damage functions are exploited. They provide an estimation of the relative damage for each identified elementat-risk, based on the inundation characteristics, which are the outcomes of the 2D hydrodynamic modelling. Although the flow velocity and the flood duration [10] may play a significant part for specific applications (e.g. dam break flows) and should be included in the analysis for such cases, the water depth remains the most influential parameter for a vast majority of applications.

The relative damage represents the percentage of the total value of goods that is lost as a result of the flood event. Consequently, combined with the monetary value of the elements-at-risk, the relative damage may be translated into an absolute economic loss.

Such a comprehensive analysis enables to compare different scenarios of flooding, possibly taking into consideration effects such as climate change or flood protection measures, and to communicate more effectively about the 
outcomes of such studies, notably because the conclusions may be expressed in terms of monetary values instead of more technical hydraulic parameters.

\section{Hydrodynamic modelling}

In order to validate the combined hydraulic-economic evaluation of the impacts of flooding, the methodology is first tested and refined for a case study area, which covers two reaches of the river Ourthe in the Meuse basin (Belgium, Figure 2). Besides, prior to evaluating the benefits of different adaptation measures, a preliminary step consists in determining how inundation hazard and its economic impact are likely to be affected by climate change. More precisely, for several return periods of floods and for a number of climate change scenarios, two-dimensional hydrodynamic simulations have been run in order to identify which modifications climate change will cause to inundation extents as well as to water depths and flow velocities in the floodplains.

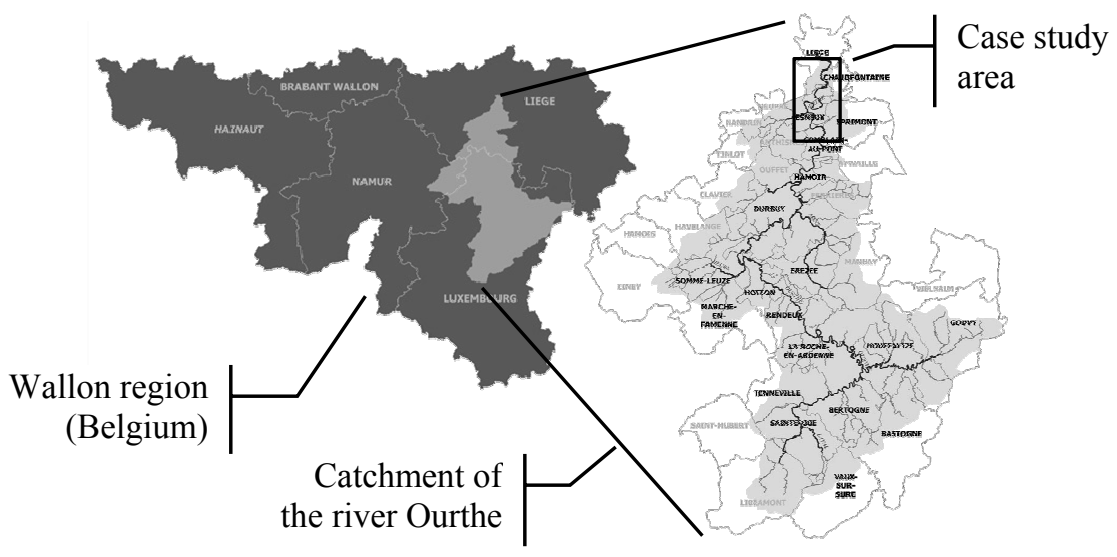

Figure 2: Location of the case study area in the catchment of the river Ourthe.

\subsection{Hydrodynamic model WOLF 2D}

The HACH research unit from the University of Liege develops a wide range of numerical tools for simulating free surface flows and transport phenomena. Those computational models are interconnected and integrated within one single modelling system named WOLF. Among those computation units, the twodimensional flow model WOLF $2 D$ is exploited for the present study and is described hereafter. WOLF 2D is based on the depth-averaged equations of volume and momentum conservation, i.e. the "shallow-water" equations [2]:

$$
\frac{\partial \vec{s}}{\partial t}+\frac{\partial \vec{f}}{\partial x}+\frac{\partial \vec{g}}{\partial y}+\frac{\partial \vec{f}_{\mathrm{d}}}{\partial x}+\frac{\partial \vec{g}_{\mathrm{d}}}{\partial y}=\vec{S}_{0}-\vec{S}_{\mathrm{f}},
$$

with $\vec{s}=\left[\begin{array}{lll}h & h u & h v\end{array}\right]^{\mathrm{T}}$ the vector of the conservative unknowns. $\vec{S}_{0}$ and $\vec{S}_{\mathrm{f}}$ designates respectively the bottom slope term and the friction term: 


$$
\vec{S}_{0}=-g h\left[\begin{array}{lll}
0 & \partial z_{\mathrm{b}} / \partial x & \partial z_{\mathrm{b}} / \partial y
\end{array}\right]^{\mathrm{T}}, \quad \vec{S}_{\mathrm{f}}=\left[\begin{array}{lll}
0 & \tau_{\mathrm{b}, x} / \rho & \tau_{\mathrm{b}, y} / \rho
\end{array}\right]^{\mathrm{T}} .
$$

$\vec{f}$ and $\vec{g}$ represent the advective and pressure fluxes in directions $x$ and $y$, while $\vec{f}_{\mathrm{d}}$ and $\vec{g}_{\mathrm{d}}$ are the diffusive fluxes.

Written out in full, these fluxes become:

$$
\vec{f}=\left(\begin{array}{c}
h u \\
h u^{2}+\frac{1}{2} g h^{2} \\
h u v
\end{array}\right), \quad \vec{f}_{\mathrm{d}}=-\frac{h}{\rho}\left(\begin{array}{c}
0 \\
\sigma_{x} \\
\tau_{x y}
\end{array}\right), \quad \vec{g}=\left(\begin{array}{c}
h v \\
h u v \\
h v^{2}+\frac{1}{2} g h^{2}
\end{array}\right), \quad \vec{g}_{\mathrm{d}}=-\frac{h}{\rho}\left(\begin{array}{c}
0 \\
\tau_{x y} \\
\sigma_{y}
\end{array}\right) .
$$

The following notations have been used: $t$ represents the time, $x$ and $y$ the space coordinates, $h$ the water depth, $u$ and $v$ the depth-averaged velocity components, $z_{\mathrm{b}}$ the bottom elevation, $g$ the gravity acceleration, $\rho$ the density of water, $\tau_{\mathrm{b} x}$ and $\tau_{\mathrm{b} y}$ the bottom shear stresses, $\sigma_{x}$ and $\sigma_{y}$ the turbulent normal stresses, and $\tau_{x y}$ the turbulent shear stress. The bottom friction is conventionally modelled thanks to an empirical law, such as the Manning formula. The models enable the definition of a spatially distributed roughness coefficient. The internal friction may be reproduced by different turbulence closures included in the modelling system, such as simple algebraic ones but also a complete depthaveraged $k-\varepsilon$ model.

The numerical model deals with multiblock Cartesian grids. This feature increases the size of possible simulation domains and enables local mesh refinements, while preserving the lower computation cost required by Cartesian grids compared to unstructured ones. A grid adaptation technique restricts the simulation domain to the wet cells. Besides, wetting and drying of cells is handled free of volume conservation error [11].

The space discretization is performed by means of a finite volume scheme. Variable reconstruction at cells interfaces is performed linearly, in combination with slope limiting, leading to a second-order spatial accuracy. The advective fluxes are computed by a Flux Vector Splitting (FVS) technique developed by the first and fifth authors. A Von Neumann stability analysis has demonstrated the stability of this FVS [4]. The diffusive fluxes are legitimately evaluated by means of a centred scheme. Since the model is applied to compute steady-state solutions, the time integration is performed by means of a 3-step first order accurate Runge-Kutta algorithm, providing adequate dissipation in time. The time step is constrained by the Courant-Friedrichs-Levy (CFL) condition based on gravity waves. A semi-implicit treatment of the bottom friction term (2) is used, without requiring additional computational costs.

The model has been extensively validated and has shown its efficiency for numerous practical applications $[4,5,8,9,11]$.

\subsection{Main assumptions and considered return periods}

Results of Global Circulation Models (GCM) and Regional Climate Models (RCM) provide estimates of the potential increase in precipitation (winter and summer) and potential changes in evapotranspiration as a result of climate change [1]. Those predicted changes are affected by a significant level of 
uncertainty due to the climate models themselves and, to an even greater extent, to the discrepancies in the scenarios used for running those climate models [13].

Moreover, translating those changes in precipitation and evapotranspiration into changes in river discharges is also a challenging task, since the catchment response depends on many factors such as the land roughness and permeability, the rainfall duration, ... Therefore, at the present stage of the ADAPT project, simple assumptions have been considered regarding the expected changes in the peak discharges of the river Ourthe as a result of climate change (CC). Indeed, according to a comprehensive literature review $[3,6,7]$, an increase by $10 \%$ of flood discharge may be regarded as reasonable. Moreover, in order to evaluate the sensitivity of the results with respect to this perturbation factor on the discharge, increases by $5 \%$ and by $15 \%$ have also been considered. Finally, a more "extreme" case has been simulated as well $(+30 \%)$. All those assumptions will eventually be confirmed and refined by comparison with the output of a hydrological model [3]. The study is performed for two different return periods, namely 25 and 100 years, for which the best adaptation strategies will be complementary, due to the significant differences in inundated areas and in the probability of occurrence.

A high resolution Digital Elevation Model (LIDAR data) is used, enabling thus to represent each street or building individually on a $2 \mathrm{~m} \times 2 \mathrm{~m}$ computation grid.

\subsection{Simulation results}

By means of hydrodynamic modelling, the assumed modifications in the discharge values have been translated into updated evaluations of inundation extent and characteristics for the considered reaches of the river Ourthe. Table 1 summarizes the different hydraulic simulations carried out. It also provides averaged values of the change in water depths for CC scenarios 1 to 3 .

Table 1: $\quad$ Mean change in water depth induced by Climate Change (CC) for two different return periods (25-year and 100-year floods).

\begin{tabular}{|c|c|c|c|c|c|}
\hline & & $\begin{array}{c}\text { Base } \\
\text { scenario }\end{array}$ & $\begin{array}{c}\text { Scenario } 1 \\
(+5 \%)\end{array}$ & $\begin{array}{c}\text { Scenario } 2 \\
(+10 \%)\end{array}$ & $\begin{array}{c}\text { Scenario } 3 \\
(+15 \%)\end{array}$ \\
\hline \multirow{3}{*}{$\begin{array}{l}\text { 25-year } \\
\text { flood }\end{array}$} & Discharge & $726 \mathrm{~m}^{3} / \mathrm{s}$ & $799 \mathrm{~m}^{3} / \mathrm{s}$ & $835 \mathrm{~m}^{3} / \mathrm{s}$ & $835 \mathrm{~m}^{3} / \mathrm{s}$ \\
\hline & Reach $n^{\circ} 1$ & - & $+25 \mathrm{~cm}$ & $+40 \mathrm{~cm}$ & $+40 \mathrm{~cm}$ \\
\hline & Reach $n^{\circ} 2$ & - & $+25 \mathrm{~cm}$ & $+40 \mathrm{~cm}$ & $+40 \mathrm{~cm}$ \\
\hline \multirow{3}{*}{$\begin{array}{l}\text { 100-year } \\
\text { flood }\end{array}$} & Discharge & $876 \mathrm{~m}^{3} / \mathrm{s}$ & $964 \mathrm{~m}^{3} / \mathrm{s}$ & $1007 \mathrm{~m}^{3} / \mathrm{s}$ & $1007 \mathrm{~m}^{3} / \mathrm{s}$ \\
\hline & Reach $n^{\circ} 1$ & - & $+30 \mathrm{~cm}$ & $+45 \mathrm{~cm}$ & $+45 \mathrm{~cm}$ \\
\hline & Reach $n^{\circ} 2$ & - & $+40 \mathrm{~cm}$ & $+60 \mathrm{~cm}$ & $+60 \mathrm{~cm}$ \\
\hline
\end{tabular}

Results have also been produced in the form of updated inundation maps, indicating, for each return period and each climate change scenario, the 2D distribution of water depth in the floodplains, flow velocity and increase in water 
depth compared to the base scenario. It is found that the results can be very sensitive to the perturbation factor affecting the discharge, due for instance to the reduced efficiency of flood protection structures (e.g. dikes) above a threshold value of discharge (design discharge). Moreover, the complexity of the flow fields represented on the inundation maps recalls the relevance of exploiting a fully two-dimensional flow model. The present set of hydrodynamic modelling results serves as an input for the subsequent economic damage modelling, but also for the evaluation of social and ecologic impacts.

\section{Economic damage modelling}

This section covers an in-depth description of the methodology developed for evaluating the economic damage induced by floods, while a short overview of the procedure was introduced in section 2 .

\subsection{Geographic database}

Accurate land use data constitute key input data in any analysis of the socioeconomic impacts of floods. In the present study, a database from the Belgian Institut Géographique National ("Top10v-GIS" - (C) IGN) is exploited. It gathers very comprehensive sets of vector data, contained in information files formatted as ESRI ShapeFiles, which can be imported within most GIS environments.

The database contains 18 layers of data, each one referring to a class of objects (e.g. administrative data, altimetry, electricity, land use, structure ...). The scale of those maps corresponds to 1:10000 and their global accuracy is 1 meter in the Lambert Belgian reference system. In this study, five different types of objects in land use and structures layers are taken into consideration: residential and industrial buildings, road networks, crops and fields, as well as forests.

\subsection{Exploitation of hydrodynamic modelling results in combination with vector land use database}

As shown in Figure 3, the estimation of the absolute economic damage may be described as a four-step procedure:

- first, the inundation extent is extracted from the inundation maps and is exploited in combination with land use data to identify the elements-at-risk;

- second, a specific damage function is assigned to each of the five classes of elements-at-risk, representing their respective vulnerability to flooding;

- next, this function is applied, in combination with the water depths (and possibly flow velocity or flood duration), to provide a relative value of the damage encountered by each object during the considered flooding event;

- finally, the relative damage is multiplied by an estimated value of the flooded element (so called: specific patrimonial value). At the end of this methodology, an absolute estimation of the financial damage induced by the flood event can be assigned to each node of the initial flood map grid.

For the case study, housing values will be collected from local cadastral offices. 


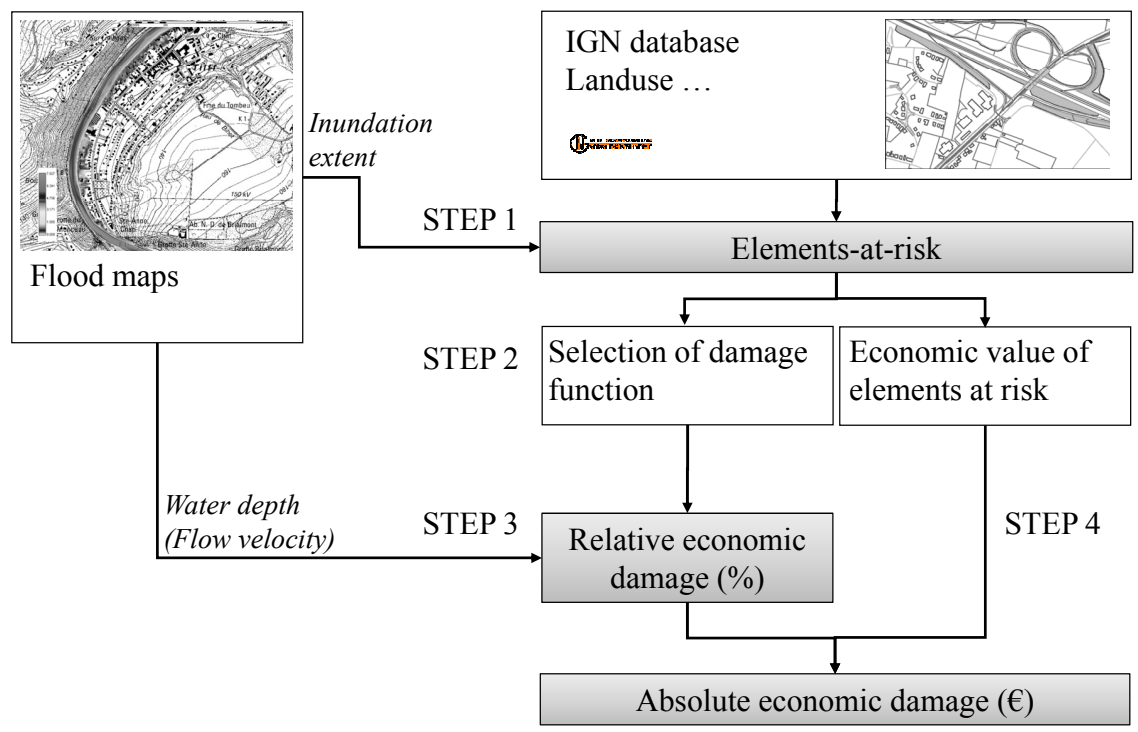

Figure 3: Flow chart describing the integration of hydrodynamic modelling results and economic damage evaluation.

It must be noted that most damage functions used for economic loss evaluations as a result of flooding depend on water depth, which is a direct outcome of the hydrodynamic simulations. However, because these numerical simulations are not run on a Digital Terrestrial Model (DTM) but on a Digital Surface Model (DSM, including anthropic over grounded objects), the value of the water depth at the location of buildings is not directly available in the output of the numerical modelling. Therefore, these water depths are calculated by means of an average of the water depth values in the vicinity of the building and are then assigned to each computation cell representing the corresponding over grounded object.

\subsection{Damage functions}

The damage functions, linking the hydraulic parameters and the type of elements-at-risk to the damage costs, can take various forms: continuous function, scale function, simple ratios, to be applied to the value of the good affected or providing a direct monetary cost of the damages ... [15]. These functions are developed either by feedback from real events (observation of damages declared after flooding), or by expert judgment (development on the basis of the experience of individuals carrying out the appraisal of loss or from building experts). Experience of the latest flooding events in Belgium shows that damages on houses are the most important contribution to the total damage compared to other sources of damages. Consistently, the present development of damage functions is focused mainly on this type of damage.

The damage functions generally link the following two parameters: 
- "water level", i.e. water depth inside the considered object (or good), measured from the floor of the habitation;

- relative damage, expressed as a percentage of the value of the affected object.

The following damage function reported in the ICPR Rhine atlas [14] is presently used: $D=2 H^{2}+2 H$, where $H$ is the water level recorded during the flooding and $D$ designates the damage in percentage of the housing value.

These functions are obtained by empirical observation of the losses and statistical processing of collected data. In other approaches, the calculation of damages is carried out directly by means of absolute damage functions [12]. The value of the assets is already integrated in the damage functions, such as for instance those provided by the Multi Coloured Manual in the UK [16].

\subsection{Development and validation of damage functions}

The methodology of the development and validation of these damage functions in the present study follows 3 steps: (i) a literature review, (ii) the application of a number of damage functions based on the results of hydrodynamic modelling for past flood events on the case study of the river Ourthe and (iii) the comparison of computed damage with reference values collected by the Belgian "Disaster Fund" after real flood events. Available data of real damages, per street and per category, contain on one hand values claimed by the population and on the other hand values eventually accepted to be supported by the "Disaster Fund". These two values differ by a factor of the order of two.

Partly due to a lack of information in the reference data collected by the Disaster Fund, computed values of damage appear to be globally overestimated according to the present preliminary comparisons. Nevertheless, as shown in Figure 4 , the economic damage modeling procedure succeeds in providing a satisfactory overall picture of the relative cost of damage caused by the major recent flooding events along the river Ourthe, namely the 1993, 1995, 2002 and 2003 floods.
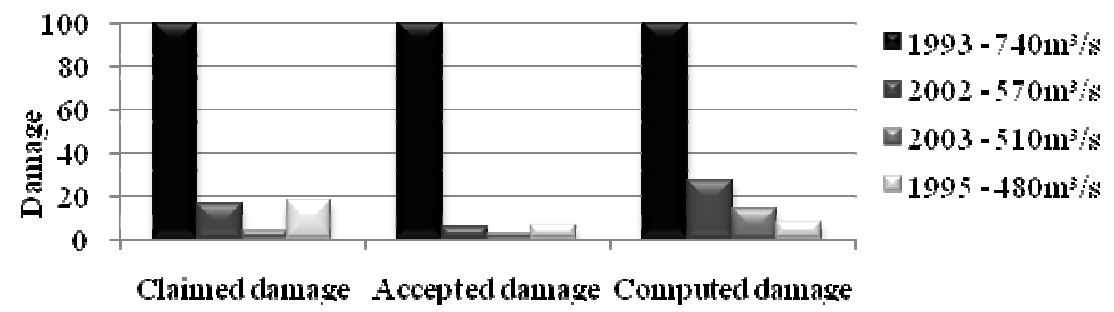

Claimed damage Accepted damage Computed damage

Figure 4: Damage claimed to / accepted by the Disaster Fund vs computed damage, expressed in percentage of the corresponding damage of the 1993-flood. 


\section{Conclusion}

The present paper describes the combination of two-dimensional hydrodynamic modelling with a procedure for economic damage evaluation in the context of climate change. The high resolution topographic data used for the flow simulations lead to very detailed flood maps, which serve as an input for computing the cost of damage. This evaluation takes into consideration the three following components: a detailed vector land use database, suitable damage functions and specific values of the elements-at-risk. The overall procedure leads to satisfactory estimations of the relative damage caused by a series of real past major flood events along the river Ourthe (Meuse Basin, Belgium).

\section{Acknowledgements}

Part of this research was carried out on behalf of the Belgian Science Policy (BELSPO), in the framework of the program "Science for a Sustainable Development". The authors also gratefully acknowledge the Walloon Ministry of Facilities and Transport (MET) for the Digital Elevation Model and other data.

\section{References}

[1] Boukhris, O., P. Baguis, P.Willems and E.Roulin, Climate change impact on hydrological extremes along rivers and urban drainage systems. II.Study of climate change scenarios. May 2007, K.U.Leuven - Hydraulics Section \& Royal Meteorological Institute of Belgium: 92 p.

[2] Chaudhry, MH, Open-Channel Flow. 1993, Englewood Cliffs: Prentice Hall, 483 p.

[3] De Groof, A., W. Hecq, I. Coninx, K. Bachus, B. Dewals, M. Pirotton, M. El Kahloun, P. Meire, L. De Smet and R. De Sutter, General study and evaluation of potential impacts of climate change in Belgium. ADAPT Towards an integrated decision tool for adaptation measures - Case study: floods. 2006, 66 p.

[4] Dewals, B., Une approche unifiée pour la modélisation d'écoulements à surface libre, de leur effet érosif sur une structure et de leur interaction avec divers constituants. 2006, Thèse de doctorat, Université de Liège, Liège: $636 \mathrm{p}$.

[5] Dewals, B.J., S. Erpicum, P. Archambeau, S. Detrembleur and M. Pirotton, Depth-integrated flow modelling taking into account bottom curvature. J. Hydraul. Res., 2006. 44(6): p. 787-795.

[6] Dewals, B.J., P. Archambeau, S. Erpicum, S. Detrembleur and M. Pirotton. Identification d'impacts locaux du changement climatique ét évaluation de mesures d'adaptation grâce aux modèles hydrologiques et hydrodynamiques Wolf. in Variations climatiques et hydrologie. 2007. Lyon, France: SHF.

[7] Dewals, B.J., R. De Sutter, L. De Smet and M. Pirotton, Synthesis of primary impacts of climate change in Belgium, as an onset to the 
development of an assessment tool for adaptation measures. Geophysical Research Abstracts, 2007. 9(11217): p. 2.

[8] Dewals, B.J., S.A. Kantoush, S. Erpicum, M. Pirotton and A.J. Schleiss, Experimental and numerical analysis of flow instabilities in rectangular shallow basins. Environ. Fluid Mech., 2008 (accepted).

[9] Dewals, B.J., S. Erpicum, P. Archambeau, S. Detrembleur, M. Pirotton, Numerical tools for dam break risk assessment: validation and application to a large complex of dams, in Improvements in reservoir construction, operation and maintenance, H. Hewlett (ed). 2006, Thomas Telford: London. p. 272-282.

[10] Dushmanta, D., H. Srikantha and M. Katumi, A mathematical model for flood loss estimation. J. Hydrol., 2003. 277: p. 24-49.

[11] Erpicum, S., Optimisation objective de paramètres en écoulements turbulents à surface libre sur maillage multibloc. 2006, $\mathrm{PhD}$ thesis, University of Liege: $356 \mathrm{p}$.

[12] FLOODSITE, Guidelines for socio-economic flood damage evaluation. 2006.

[13] Intergovernmental Panel on Climate Change, Climate change 2007: Synthesis Report - Summary for policymakers.

[14] International Commission for the Protection of the Rhine, ICPR Rhine atlas. 2001.

[15] Ledoux consultants, Cereve and Cemagref, Synthèse des évaluations socioéconomiques des instruments de prévention des inondations, Rapport au Ministère de l'écologie et du développement durable.

[16] Penning-Rowsell, E.C., C. Johnson, S.M. Tunstall, S.M. Tapsell, J. Morris, J.B. Chatterton, A. Coker and C. Green, The Benefits of Flood and Coastal Defence: Techniques and Data for 2003, Flood Hazard Research Centre, Middlesex University.

[17] Van der Sande, C.J., S.M. de Jong and A.P.J. de Roo, A segmentation and classification approach of IKONOS-2 imagery for land cover mapping to assist flood risk and flood damage assessment. International Journal of Applied Earth Observation and Geoinformation, 2003. 4: p. 217-229. 